\title{
Jovens de classes médias infratores e a questão da autoridade
}

\section{Medium class youngsters in conflict with the law and the authority issue}

\author{
Samira Safadi Bastos* \\ Bélgica

\section{Elaine Pedreira Rabinovich*} \\ Universidade Católica de Salvador-UCSAL, Salvador, Bahia, Brasil
}

Université Catholique de Louvain, Ottignies-Louvain-La-Neuve, Walloon-Brabant,

\begin{abstract}
RESUMO
A questão norteadora deste trabalho foi como os jovens de classe média, em conflito com a lei, percebem o seu ingresso e permanência na criminalidade. Participaram deste estudo de caso seis jovens urbanos, entre 16 anos e 19 anos, de ambos os sexos, três dos quais sentenciados e três que não passaram pelo sistema judiciário. Os critérios para a classificação dos jovens como classes médias foram: renda, bairro de residência da família, ocupação e escolaridade dos pais. Dois níveis de análise foram vistos nos resultados: dimensões societárias, familiares e individuais, e dinâmicas relacionais, uma delas referente ao exercício da autoridade e ao uso de limites, enfatizados pelos participantes como uma questão central para o ingresso e permanência na criminalidade. A ausência de um lugar social legítimo de pertencimento dos jovens apontou para a necessidade de (re)construção de valores, assim como de seus ambientes familiares e comunitários.
\end{abstract}

Palavras-chave: juventudes, família, classes médias, ato infracional.

\begin{abstract}
This work guiding question is how middle classes young people, in conflict with the law, perceive their entrance and permanence in criminality. Six urban young people, 16-19 years-old, both sexes, participated of this case study, three sentenced and three who did not pass by the juridical system. The standards used to classify young people as middle class were: revenue, neighborhood where the family lives, occupation and educational level of their parents. Two analysis levels took place as results: social, family and individual dimensions, and relational dynamics, one of these concerned to the exercise of authority and use of limits emphasized by the participants as a core issue referred to entrance and permanence in criminality. The absence of a legitimate social place of belongingness pointed to the need of (re) construction of values and family and community environments.

Keywords: youths, family, middle classes, infractional act.
\end{abstract}




\section{I ntrodução}

Adolescentes pertencentes a classes sociais baixas, que não tiveram muitas oportunidades formais de desenvolvimento, através do acesso aos direitos sociais, como educação, cultura adquirida, formação de capital social, geralmente são considerados mais propensos às influências das vulnerabilidades contemporâneas e à criminalidade. Porém, quais seriam as motivações para o ato infracional por parte daqueles que teoricamente tiveram acesso a uma escola privada, à escola de línguas, a esportes, à cultura adquirida, ao lazer, dentre outras possibilidades? Que outras questões atravessariam o ingresso e/ou a permanência em contextos criminais ilícitos? ${ }^{1}$.

Este estudo tem como objetivo compreender a visão das trajetórias de vida por adolescentes de classes médias $^{2}$ em conflito com a lei a partir deles próprios e das relações por eles construídas em determinados contextos sociofamiliares e historicoculturais, enfocando a questão da autoridade parental.

A (re)construção constante da relação entre o indivíduo e o meio conduz a pensar com o sujeito, a partir dele próprio e do que carrega do meio em que vive e com o qual constrói redes de significações, de forma dialética. (ROSSETIFERREIRA; AMORIM; SILVA; CARVALHO, 2004).

De fato, questões sociológicas e psicológicas, vistas como dois lados de um mesmo universo - o humano -, entretecem-se continuamente, retro alimentando-se, e podem indicar ao pesquisador aproximações a ambas as perspectivas, sem necessariamente haver desconsideração de uma ou de outra.

\section{Delimitação sócio-psicológica do campo da problemática}

Vários estudos realizados, no Brasil, apontam elementos que ajudam a delinear o campo deste trabalho. Esses autores refletem a importância do contexto em que os jovens se desenvolvem.

O trabalho realizado por Alcântara (2001) a partir dos relatos dos próprios jovens apontou que a qualidade da interação da família e a congruência dos projetos de vida são mediadores importantes, além das condições do contexto presentes e disponíveis. A violência e a dificuldade de inserção social se apresentaram como as principais dificuldades para os adolescentes.

Silva (2003), na contramão do entendimento de que as entradas e saídas do crime são marcadas por momentos de escolha e tomada de decisão claramente definidas, apontou a não delimitação destes 
momentos, aos quais a autora chama de (des)continuidades no envolvimento com o crime.

Assis (1999) relata que o papel da família parece passar por crises no que diz respeito às suas funções sociais. A escola aparece relatada pela maioria dos jovens como instituição que fracassou em suas funções socialmente estabelecidas, e que não representa as suas necessidades e anseios. A autora sinaliza ainda para a banalidade como a vida é vista pelos jovens entrevistados, a negação dos próprios direitos e dos direitos do outro, prevalecendo os valores da sociedade de consumo: vantagens financeiras e prestígio social.

O estudo de Borges e Alencar (2006) situou a motivação do transgressor sem delimitar previamente classes ou estratos sociais, voltados para o adulto homicida. Para as autoras, a motivação a partir dos valores morais foi vista através do que chamam de Juízo de Representação da Realidade - JRR - que seria o motivo (o que é) que levou a cometer o crime, enquanto o Juízo de Valor Moral - JVM (o que deve ser) corresponderia à aprovação ou desaprovação desta ação por parte do transgressor.

Além de maior grau de vulnerabilidade dos jovens de classes baixas, razões ligadas à impunidade das classes médias e altas brasileiras, onde estariam envolvidas questões de corrupção, e da incapacidade jurídica do adolescente desfavorecido do ponto de vista institucional, socioeconômico e cultural defender-se juridicamente, torna este estudo extremamente difícil pelo simples fato dos primeiros geralmente não estarem privados de liberdade no Brasil em números estatisticamente representativos, como mostram as pesquisas de Volpi (1997) e a de Silva e Guerese (2003), em que dados de escolaridade, raça/cor e renda familiar ratificam uma constatação, também presente no sistema penitenciário reservado para adultos: são as classes mais baixas que massivamente são privadas de liberdade.

No trabalho de Silva e Guerese (2003), baseado em dados coletados em 2002, 60\% deles eram afro-descendentes, $66 \%$ do total adolescentes viviam em famílias cujo rendimento mensal variava de menos de 1 até 2 salários mínimos, e 89,6\% daqueles na fixa etária entre 16 e 18 anos não concluíram o ensino fundamental.

Na pesquisa de Volpi (1997), em dados coletados nos anos de 1995 e 1996, verificou-se que $96,6 \%$ dos adolescentes privados de liberdade não concluíram o ensino fundamental, considerando que a maioria deles tinha na época entre 15 e 21 anos e 90,90\% tinham renda familiar até três salários mínimos.

No caso do estado da Bahia, não foram encontrados dados específicos da privação de liberdade de adolescentes; porém, trouxemos à análise o que estava mais próximo ao nosso tema. Segundo a Promotoria de Justiça da Infância e Juventude de Salvador (ALMEIDA; TAPARELLI, 2004), os jovens que cometem atos infracionais em 
Salvador estão em “(...) bairros pobres para viver e morrer, bairros ricos para roubar e matar". (p.19). E ainda, das adolescentes que cometeram atos infracionais no ano de 2000 (ARAÚJO, 2004): “A maioria delas está atrasada no calendário escolar, evidenciando um baixo nível de escolarização e atraso na relação idade/série escolar." (p.72), frequentando as chamadas séries de aceleração, em curso noturno e na rede pública de ensino. Sobre o local de moradia das mesmas adolescentes, Araújo (2004) constatou que a Chapada do Rio Vermelho, Pau Miúdo, Sete de Abril e Subúrbio Ferroviário reuniam a maioria das infratoras com entrada na $2^{\text {a }}$ Vara da Infância e da Juventude de Salvador no ano 2000. (p. 73).

Assim, ao iniciar a busca de jovens para a pesquisa em Salvador, no mês de julho de 2007, não havia nenhum adolescente considerado pelas equipes técnicas do Centro de Atendimento Sócio-Educativo CASE de Tancredo Neves, como proveniente de classes médias e/ou altas; ou seja, não haveria possibilidade de pesquisa quantitativa, documental e institucional sobre eles. E ainda, segundo informações da Diretoria do CASE supracitado, na Unidade de Simões Filho também não encontraríamos o perfil ora buscado. A sugestão foi de que buscássemos a Central de Medidas Sócio-Educativas em Meio Aberto - CMSEMA, conforme melhor detalhamento no capítulo referente ao método onde alguns jovens puderam ser acessados.

Donde optamos pela realização de uma pesquisa qualitativa, em profundidade, a partir de histórias de vida, buscando entender, através dos próprios adolescentes, em que contextos as questões foram ocorrendo em suas vidas. Este formato de pesquisa foi pensado em função de haver poucos estudos sobre criminalidade e classes médias juvenis, e ainda pela grande dificuldade de acessar estes casos, de pesquisar em quantidades maiores e que não suscitassem confiança para os pesquisados e suas famílias. Desta forma, após uma busca através de contatos e vínculos de confiança, chegamos também a mais três jovens que não tinham passado pelo sistema penal brasileiro.

\section{Aportes teóricos}

A passagem da modernidade - tão marcada pelo uso da razão cartesiana, pela centralidade no homem, acima da natureza e da religião - para a pós-modernidade, traz com ela elementos do hedonismo e, obviamente, do consumismo exacerbado. Essa mola do sistema capitalista de produção, no sentido de criar cada vez mais novos consumidores potenciais e novas necessidades, tem uma influência contundente na constante construção das identidades das juventudes. Estas, na busca constante de ser pessoa no mundo, de 
afirmação e de pertencimento, são bombardeados pelos apelos ideológicos do ter - para ser cotidianamente.

Contudo, no centro da contradição da modernidade, em que o desejo de vivenciar plenamente o individualismo, que mesmo sendo direito de todos, só é possível para poucos, as sociedades “(...) foram obrigadas a dar conta das estruturas do estado-nação e das grandes massas que fazem uma democracia moderna (...)" (HALL, 2000, p.29).

As ideias pós-modernistas parecem surgir na década de 70 no cenário artístico e intelectual caracterizadas pela continuação das idéias hedonistas e individualistas e entendida como prolongamento da modernidade, contudo tendo componentes a mais o narcisismo como a presença marcante da indiferença, o que Lipovetsky (2005) chama de reinado indiferente da igualdade. Está distante da eloquência dos vanguardistas no seu ódio à tradição, onde “(...) é liberado da culpabilidade moral (...)" (p. 85). Trata-se, segundo Lipovetsky, de um individualismo pautado nos desejos de si mesmo sem querer fazer uma contraposição a qualquer coisa, costumes ou ideologias:

(...) deixou de existir a tensão entre os artistas inovadores e o público porque ninguém mais defende a ordem e a tradição, havendo uma democratização do hedonismo destituída de indignação, cuja "realização definitiva do indivíduo coincide com a sua dessubstancialização, trazendo uma (...) inclinação à angústia $e$ à ansiedade (...). (LIPOVETSKY, 2005, p. 85).

É uma sociedade dotada, pelo menos no nível do discurso, do poder da escolha, da convivência das diferenças, mesmo que esta "escolha" seja, não por acaso, a de ser igual a todos os outros consumistas, e, portanto, mais igual do que desejadamente diferente. 0 neonarcisismo é marcado pela convivência "pacífica", em certos aspectos, hipócrita, de lados antes opostos. É o “(...) tempo em que as oposições rígidas se esfumaçam, em que as preponderâncias se tornam fluidas (...)". (LI POVETSKY, 2005, p. 60).

A modernidade não ocorreu no Brasil como na Europa:

A democracia no Brasil foi sempre um lamentável mal entendido. Uma aristocracia rural e semi-feudal importou-a e tratou de acomodá-la, onde fosse possível aos seus direitos ou privilégios, os mesmos privilégios que tinham sido, no Velho Mundo, o alvo da luta da burguesia contra os aristocratas. (HOLANDA, 1995, p. 160).

Porém, a democracia foi absorvida juntamente com as nossas raízes familiaristas: 


\begin{abstract}
Aqui, e Schwarz é exímio nestas revelações, as idéias da modernidade entram no repertório da elite como ornamento - o que já fora percebido por Sério Buarque de Holanda - e, pior, como consagração dissimulada daquilo mesmo que a modernidade combate: a elitização, o regime personalizado e personalizante das relações particulares, dos negócios entre amigos - as negociatas - da proteção aos parentes e afilhados, dos favores e jeitinhos. (FIGUEIREDO, 1995, p. 51).
\end{abstract}

Está presente no pós-modernismo a contradição entre a eficiência racional, na lógica da produção e do desejo de satisfação pessoal, flexível, permissiva e contraditoriamente utópica por vezes. Ainda contamos como componente do fenômeno da pós-modernidade e da globalização, a presença da desestabilização, da flexibilização das relações, contundentes quando se tratam de relações de trabalho, como em Adeus ao Trabalho? (ANTUNES, 1995) e em Terceirização: (des)fordizando a fábrica - um estudo do complexo petroquímico (DRUCK, 1999).

A força desse segundo individualismo parece inclinar para uma complacência ante as desigualdades sociais mais do que às proibições que se referem à esfera da nossa vida privada. Neste panorama, quais são os valores das famílias brasileiras e quais espelhos a atual conjuntura de inúmeras carências ético-políticas positivas reflete para os indivíduos que estão em processo de formação de sua personalidade?

Esta complacência foi observada por Waiselfisz (1998) dado que, na percepção de alunos(as) da escola particular em Brasília sobre o assassinato do índio Galdino, haveria certa amenização, considerando a infração cometida como uma forma de brincadeira que "não deu certo" (crivo meu) (p. 128), sem a intenção de matar.

Se a passagem para a modernidade na Europa foi marcada pelas lutas da burguesia e pelo fim do império, entendidas sob lemas contraditórios e inexequíveis por serem incompatíveis entre si, o que ocorreu no caso brasileiro, em que do patriarcalismo passou quase que diretamente à pós-modernidade? De uma forte autoridade familiar à sua ausência?

A crítica moderna ao modelo patriarcal e autoritário de família fez com que a obediência fosse exigida pelo uso da razão (HORKHEIMER, 2002). A educação contemporânea doméstica, ao negociar a obediência do filho, ilustra tal consequência.

Deste modo, no presente momento, o campo psicossocial de nosso estudo se organiza a partir das seguintes questões, entre outras: Como se configura a ética na constituição da subjetividade, em termos contemporâneos, sem a hierarquia e sem a autoridade de outrora como princípios balizadores? Diante do declínio da autoridade parental e do patriarcado, estaria ocorrendo a ausência e/ou 
enfraquecimento da autoridade nos meios de socialização da pessoa, culturalmente reconhecidos como pilares regulatórios?

\section{Método}

Participaram deste estudo seis jovens entre 16 anos e 19 anos, de ambos os sexos, três dos quais sentenciados e três que não passaram pelo sistema judiciário. A pesquisa foi iniciada na Central de Medidas Sócio-Educativas em Meio Aberto (CMSEMA), Salvador, Bahia, tendo como foco os casos que foram selecionados como classe média pelos critérios de renda, bairro de residência da família, ocupação e escolaridade dos pais, utilizados de forma cumulativa. Dentro do universo supracitado e selecionado, estavam 07 (sete) jovens, no intervalo dos (quase) três anos de existência da CMSEMA. Estes jovens estavam em fases diferentes do cumprimento das medidas: alguns não tinham ainda cumprido, outros estavam em cumprimento e havia um que já tinha finalizado o cumprimento da sentença determinada pelo Juiz. A pesquisa foi realizada com três destes jovens conforme relatado acima.

Reforçando a percepção da dificuldade de acesso a tais jovens, nenhum desses pesquisados e suas famílias compareceu ao primeiro encontro agendado para consulta ou entrevista. Tais dificuldades alertaram para a necessidade de se ampliar o número de depoentes, o que foi realizado pela inclusão de três jovens que cometeram atos infracionais sem ter passado pelo sistema judiciário. Estes três jovens foram escolhidos a partir de aproximação familiar e indicação de amigos mais próximos que passaram alguns anos do início da adolescência envolvidos com diversas infrações, até as respectivas famílias se darem conta e/ou buscarem ajuda de equipes profissionais e tratamento. Os três se encontravam em fase de recuperação. Os critérios de inclusão na amostra foram idade do jovem entre 15 e 24 anos (intervalo estabelecido pela Organização Mundial de Saúde OMS); contextos urbanos, em função da suposição de que, na atual conjuntura, a criminalidade juvenil se configura de forma mais latente na urbanidade do que em contextos rurais, ou ao menos bastante diferenciada; e classificação do estrato sociocultural, no qual estabelecemos como norteadores os critérios cumulativos de escolaridade e ocupação dos pais, renda familiar e padrão de consumo (nele incluído o bairro/condições de moradia) (POCHMANN; PEREIRA; BARBOSA; SILVA; AMORIN, 2006).

$O$ estudo foi realizado por meio de entrevistas livres e individuais, as quais foram gravadas e, posteriormente, transcritas pela pesquisadora. Foi realizada uma pesquisa documental dos casos de adolescentes cumprindo medida na Central anteriormente citada, pela 
leitura dos prontuários e relatórios das equipes técnicas, além das conversas com as técnicas de apoio de cada jovem.

Após reiteradas leituras das transcrições das entrevistas, tanto diacronicamente - tentando a dinâmica pertinente a cada um dos jovens, quanto sincronicamente - procurando os elementos comuns entre eles, emergiram eixos interpretativos de análise. Os resultados serão apresentados por meio dessa análise interpretativa, centrada em alguns desses eixos que não esgotam, contudo, o tema, mas que buscarão fazer o alinhavo analítico entre as questões macrosistêmicas e micro-sistêmicas. Será apresentado no presente trabalho o tema central da questão da autoridade.

\title{
5 Resultados e discussão: a questão da autoridade
}

As composições familiares são diversificadas nas histórias dos seis entrevistados - há as nucleares, monoparentais e as ampliadas.

\begin{abstract}
Desde que eu nasci que meu pai não mora com a gente. Minha mãe se separou dele (do padrasto), tem mais ou menos um ano... Na verdade é legal ainda porque ele se separou, mas mora no apartamento em frente ao nosso, porta com porta. É nosso vizinho, por enquanto... E sempre fica com as portas abertas, meu irmão vai lá, ele vem cá.... (Jovem 1).
\end{abstract}

Porém, o que pareceu influenciar diretamente na concepção de criminalidade dos jovens foi a indefinição, e possível incoerência, no exercício da autoridade em cinco dos seis casos.

(...) Eu lembro de quando o Painho chegava pra gente passar o fim de semana com ele e eu não queria ir, eu queria ficar em casa, mas a maioria das vezes eu tinha que ir... (...) Porque eu tinha medo, medo do Painho. (Jovem 4).

Esta indicação dos jovens ora pesquisados pode estar remetendo ao que Horkheimer (2002) já apontara para a possível produção, pelo patriarcalismo, de figuras neuróticas e ao mesmo tempo produtoras de ordem, e para o papel da autoridade (e não do autoritarismo) como possível dispositivo regulador da família e das relações sociais. Estas questões podem ser consideradas como o campo psicossocial para a criminalidade juvenil, sendo a relação com o pai mais um dos elementos entrelaçados com o exercício da autoridade como demonstra o trecho que segue:

(Sobre a relação com o pai): (...) Ele fica quinze dias aqui e quinze dias na fazenda. Sinto falta dele, mas é desde pequena, minha relação sempre foi mais com minha mãe, a 
gente nunca foi de tá conversando, ele é um bicho do mato, ele não conversa com a gente. Quando chega da fazenda, se entoca e não conversa com ninguém. (...) Assim, quando eu queria ir pro show e tava namorando, ele dizia: 'Não vai não, com namorado, assim, não sei o quê...' Aí não dava dinheiro. Mas eu arranjava, vendendo droga, e ia mesmo sem o dinheiro dele. (J ovem 3).

Estudos de Goldenberg (1998) mostram a complexidade desta relação acrescentando uma dimensão a esta complexa rede que permeia o exercício da autoridade, afirmando que o pai simbólico estaria ausente nas crianças e nos adolescentes infratores pesquisados: “( ...) vivem uma situação dual, ou seja, imaginária, em que o terceiro não entrou na constelação familiar." (GOLDENBERG, 1998, p. 113). Para a autora, a ausência da lei paterna no lar é uma das razões para o início de adolescentes estarem em conflito com a lei.

A afirmação de si e do masculino foi presente nos relatos dos cinco jovens, como demonstra o trecho que segue e ainda na fala da jovem, porém de maneira diferenciada.

(Falando sobre a prática da infração cometida por outros jovens): Todo mundo ficava glorificando ele... É esse negócio que a galera pensa... Que a pessoa que impor o respeito ali, vai ficar respeitado..." (Falando sobre os anseios atuais) "Eu sempre quis ir pro exército, eu via aqueles negócios na televisão, entendeu? Cheio de vibração. Eu ficava pensando naquele negócio de se arrastar no mato... Eu queria ir pro exército, mas na hora o cara lá botou Marinha. Também o cara vai iludido, porque hoje em dia não segue mais carreira, antigamente seguia, né? Mas às vezes eles fazem uma pressão da porra. (Jovem 1).

Cinco dos seis entrevistados da presente pesquisa apontaram a importância dos limites na educação parental - tanto aqueles que consideram que os tiveram em casa, quanto os jovens cujo entendimento era a necessidade de mais limites do que os que foram colocados pelos pais, como ainda o entrevistado detentor de um limite imposto por rigidez excessiva e percebida como violenta.

( $A$ entrevistadora pergunta por que ele voltou para a casa da mãe): Rapaz, eu... Engraçado, eu tive uma conversa ontem com a minha mãe exatamente sobre isso, eu acho que foi um pedido de socorro. Acho que foi... Um pedido de socorro... Lá ( na casa do pai), se eu saísse no sábado, eu voltava no domingo de noite e ninguém falava nada. Aqui com 14, 13 anos de idade e fizesse um negócio desse, minha mãe, ah, meu Deus! Eu ia escutar até o outro dia. Fazia de novo, mas eu sabia que toda vez que eu fizesse, eu ia ter 
aborrecimento, e lá não tinha. Mas eu acho que foi um pedido de socorro inconsciente, sabe? (J ovem 5).

Neste sentido, estamos admitindo a possibilidade de que a ordem familiar existente anteriormente foi sendo substituída por uma atual "des/ordem" (ROUDINESCO, 2003), onde a autoridade da casa foi sendo segmentada e substituída por instituições externas a ela, como o Estado.

(A entrevistada explica porque quis mudar de colégio): É porque no colégio antigo não podia nem sair do Colégio. No colégio novo, o portão ficava aberto, saía quem quisesse. (No antigo) Não podia nem cortar a camisa, não podia ir de boné, não podia nada no Colégio. O colégio novo era mais liberal. Muito preso, acaba botando a galera pra querer liberdade, é pior. (Jovem 3).

Para Roudinesco (2003), há um cemitério das referências patriarcais, das figuras de autoridade, como o exército e a escola, donde restaria apenas a família, em uma sociedade que condena o ser humano à horizontalidade de uma economia de mercado, onde somos todos iguais e não somos ninguém. Para a autora, a família aparece como a única capaz de assumir o conflito e favorecer a emergência de uma nova ordem simbólica, sem a qual ocorreria a anomia social, pois ela se estrutura pela diferença entre os sexos e as gerações. A presença destas diferenças é que seria a articuladora da ordem social.

(O entrevistado explica como foi a mãe entregar os dois filhos à polícia face aos atos infracionais por eles cometidos): Não, ela disse: "amanhã de manhã, eu vou levar vocês não sei aonde". Aí quando foi... Eu e meu irmão entrou no carro e ela levou a gente lá e disse: 'Eu soube que vocês estavam, fazendo isso e isso e isso...'. A gente não sabia o que era. Porque ela falou que se perguntasse a gente não ia falar e realmente ia ser isso mesmo. Ia ficar difícil. Ela levou e foi e melhor coisa que aconteceu mesmo. (...) Se não fosse minha mãe... Querendo ou não ela salvou a gente. (J ovem 2).

Teve um dia que louco, já louco, eu esqueci a droga, lá, uma parada da droga, dez reais se eu não em engano, e quando meu pai abriu o quarto de manhã para me chamar pra ir para o colégio, ele viu né? Meu pai tomou um choque ali, não bateu em mim, mas falou, né, demais, disse: "Por que você tá usando isso? O que é que você vai ganhar?" (...) Ele agiu assim, só que foi a primeira vez, ele tinha que fazer assim, acho que como uma primeira vez, ele deveria ter agido assim comigo sim, devia ter sido mais firme, ter dado uma surra, assim... Não de tirar sangue, de deixar roxo, mas até dar mesmo e algum, sem bater, bater mesmo também, ou até uma experiência que ele tenha tido, me falar, mas eu não sei assim, se meu pai usou outras drogas, não sei... (J ovem 6). 
A rejeição ao conceito de figuras de autoridade está ligada, conforme Sennett (2001), ao fim do antigo regime monarca, onde na Europa a herança deixada pela Revolução Francesa foi a crença de que a autoridade não pode estar ligada à legitimidade e sim à razão, causando uma cisão entre as duas - autoridade e legitimidade, à medida que o poder da monarquia poderia ser destruído através da desmoralização de sua legitimidade, e à incitação nas massas do desejo de liberdade. "(..) a aura de autoridade do rei, enquanto houvesse um rei, inibia os revolucionários, na mudança das estruturas fundamentais da sociedade". (SENNETT, 2001, p. 60).

\begin{abstract}
Meu pai é um bicho, é um grosso! Eu odeio ele! Ele é um saco, um chato. Tenho raiva dele muitas vezes, muitas vezes mesmo! (falava com uma expressão de raiva). Minha mãe é que sempre resolve tudo. É minha mãe... (J ovem 3).
\end{abstract}

A anotar, na fala de jovem acima, a força da figura materna, em contraposição à paterna, como está ocorrendo no mundo inteiro, segundo o estudo de Georgas, Berry, Vijner, Kagitçibasi e Poortinga (2006), realizado em 30 países, inclusive no Brasil, e que verificou igualmente a diminuição do valor da hierarquia nos jovens entrevistados.

Mesmo cientes das controvérsias quanto a ter havido ou não o que se convencionou chamar de modernidade e pós-modernidade no Brasil, a ausência de um delineamento de como estas questões foram construídas ao longo da história brasileira não significa que não pesem sobre as formas (ideológicas) de socialização das sociedades e das juventudes contemporâneas.

\title{
6 Liberdade e limites
}

Cinco dos seis entrevistados da presente pesquisa apontaram a importância dos limites na educação parental - tanto aqueles que consideram que os tiveram em casa, quanto os jovens cujo entendimento era a necessidade de mais limites do que os que foram colocados pelos pais, e ainda o entrevistado detentor de um limite imposto por rigidez excessiva e percebida como violenta.

Hoje em dia ela fala até que se arrepende de ter me batido. É porque a pessoa só vê assim, quando se separa (os pais são separados). Ela se separou da gente assim, aí ela fala. 'Ah, eu bati em vocês, nenhuma mãe quer bater, mas às vezes tem que bater, né?' Mas é, senão o filho quer mandar na mãe, e hoje em dia o mundo ta aí... 'A gente tem que dar um basta, né?' (...) Claaaro que tem que ter limite (dito com ênfase). Tem que ser, tem que ser. (J ovem 1). 
Lá (no colégio novo) era muito aberto, a gente podia fumar maconha toda hora... Eu acho que se eu tivesse ficado no antigo colégio não tinha acontecido isso tudo não, porque era mais calmo mesmo". Entrevistadora - 'Então um pouco de limites talvez fosse bom no colégio...' “É, um pouco, mas muito rigoroso também não adianta. (Jovem 3).

Talvez o alongamento da juventude, o seu endeusamento pelas outras gerações, mudanças na configuração da família (como o enfraquecimento da autoridade paterna, maior ausência da mulher no lar pela inserção no mercado de trabalho, diminuição considerável do número de filhos, dentre outros), além dos valores de consumo onde o jovem é "célula" consumidora - e da individualidade trazidos pela modernidade, tenham composto um quadro de poucos limites para o que convencionalmente chamamos de juventudes (CASTRO; ABRAMOVAY, 2005).

(A relação): Era melhor quando eu era pequena, mas quando eu comecei a sair, ele começou a reclamar: 'Não sei o quê, pra onde você vai? Tem que estudar!' (imitando um tom agressivo de falar). Fica querendo me prender, mas eu tenho que curtir. Depois eu vou ficar velha acabada e vou curtir mais o quê? Tá louco? (J ovem 3).

Não se pode deixar de fazer o contraponto com o primeiro item abordado acima, que trata da questão da dificuldade do uso da autoridade - mesmo sendo uma coisa reconhecidamente como necessária, a contemporaneidade tem apontado inúmeros obstáculos no seu exercício.

\section{7 À guisa de conclusão}

Por ser este um trabalho inserido em uma rede contemporânea de entrelaces, propondo refletir com os jovens sobre uma questão tão próxima ao senso comum, e exposta cotidianamente na mídia, as percepções dos entrevistados devem ser tratadas de modo extremamente cuidadoso, apenas como uma das possibilidades de interpretação.

A criminalidade juvenil de autoria ligada aos jovens de classes médias e altas brasileiras é uma manifestação inscrita na matriz sociohistórica - além de suas outras múltiplas dimensões - a partir de questões que ultrapassam a associação exclusiva com a classe, sendo assim entendida por nós como transclassistas e imprimindo múltiplas determinações. O presente trabalho não pretende minimizar a profundidade e a seriedade das questões de classe e de distribuição de renda no Brasil, mas elucidar aspectos que afetam toda a 
juventude brasileira. Busca tornar compreensível um fenômeno que a mídia tem mostrado como crescente, que é a criminalidade atribuída a esta faixa etária.

Algumas questões podem estar interferindo no exercício da autoridade paternal e societária: como o alongamento da juventude sob vários aspectos, por exemplo, no aumento do número de anos de estudo e de moradia com os pais; no seu endeusamento pelas outras gerações e pela indústria do consumo; nas mudanças na configuração da família (como o enfraquecimento da autoridade paterna, maior ausência da mulher no lar pela inserção no mercado de trabalho, diminuição considerável do número de filhos, dentre outros); nos valores de consumo - onde o jovem é "célula" consumidora -; e da individualidade trazidos pela modernidade. Todos estes elementos podem ter composto um quadro de poucos limites para o que se convencionalmente chamamos de juventudes (CASTRO; ABRAMOVAY, 2005).

Presenciamos um duplo equívoco, refletido em um formato de Estado que se construiu como substituinte da autoridade, fazendo cada vez mais intervenções na família, porém de forma mínima, entregando ao núcleo familiar atribuições que não the cabem e, ao mesmo tempo, interferindo em questões antes consideradas privadas.

Enquanto isso, muitos dos nossos jovens buscam referenciais de autoridade em ambientes externos ao familiar e àqueles considerados "pedagogizantes", abrindo espaço para o ingresso e permanência na criminalidade. Eles buscam na rua também o pertencimento com os co-etanos. Poderíamos chamar de casa e rua ou de privado e público, os espaços domésticos e comunitários, porém não o faremos para evitar deslizes de conceituação dessas nomenclaturas, as quais são associadas a muitos significados que não se constituem nosso centro de discussão. Queremos tratar da condição de pertencimento que é inerente ao jovem, e se traduz em uma necessidade tão concreta quanto comer todos os dias.

Essa importante condição nos faz perceber que se nestas dimensões doméstica e comunitária - não estiverem presentes a autoridade e a proteção como lastros balizadores nas relações (re) produzidas nos dois lócus, como instâncias privilegiadas de socialização dos sujeitos, os papéis e os limites não estarão bem estabelecidos, fazendo com que as margens se mesclem em direção desconhecida. Portanto, com a ausência de um lugar social legítimo na sociedade, os nossos jovens pertencem a ninguém.

\section{Referências}

ALCÂNTARA, M. A. R. d. Modos do adolescente enfrentar o risco: um estudo longitudinal sobre projetos de vida no contexto da 
família. 2001. 120f. Dissertação (Mestrado) - Instituto de Saúde Coletiva, Universidade Federal da Bahia, Salvador, 2001.

ALMEIDA, A.; TAPPARELLI, G. O perfil dos adolescentes em conflito com a lei representados pela Promotoria da Infância e da Juventude em Salvador (2000-2003). Disponível em: <http://www.altrodiritto.unifi. it>. Acesso em: 03 ago. 2008.

ANTUNES, R. Adeus ao trabalho? Ensaio sobre as metamorfoses e a centralidade no mundo do trabalho. 13a ed. revista e ampliada, São Paulo: Cortez, 1995.

ARAÚJ O, D. B. d. O perfil das adolescentes que cometeram atos infracionais em Salvador no ano 2000. 2004. 129f. Dissertação (Mestrado) - Psicologia, Universidade Federal da Bahia, Salvador, 2004.

ASSIS, S. G. de. Traçando caminhos em uma sociedade violenta: a vida de jovens infratores e de seus irmãos nãoinfratores. Rio de J aneiro: Editora FIOCRUZ, 1999.

BORGES, L. S.; ALENCAR, H. M. d. Moralidade e homicídio: um estudo sobre a motivação do transgressor. Psicologia, Reflexão e Crítica, Porto Alegre, v. 19, n 3, p. 451-459, 2006.

CASTRO, M. G.; ABRAMOVAY, M. Juventudes no Brasil: vulnerabilidades negativas e positivas, desafiando enfoques de políticas públicas. In: CAVALCANTI, V. R. S.; PETRINI, J. C. (Orgs.). Família, sociedade e subjetividades: uma perspectiva multidisciplinar. Petrópolis: Vozes, 2005, p. 54-83.

DRUCK, M. d. G. Terceirização: (des)fordizando a fábrica - Um estudo do complexo petroquímico. Salvador: EDUFBA, 1999.

FIGUEIREDO, L. C. Modos de subjetivação no Brasil e outros escritos. São Paulo: ESCUTA/EDUC, 1995.

GEORGAS, J.; BERRY, J. W.; VIJNER, R. V. D.; KAGITÇIBASI, Ç.; POORTINGA, Y. P. Families across cultures. A 30-nation psychological study. Cambridge: Cambridge University Press, 2006.

GOLDEMBERG, G. W. O pai simbólico está ausente na criança e no adolescente infratores. In: LEVISNKY, D. L. (Org.). Adolescência pelos caminhos da violência: a psicanálise na prática social. São Paulo: Casa do Psicólogo, 1998, p.113-128.

HALL, S. A identidade cultural na pós-modernidade. 4a ed. Rio de Janeiro: DP\&A, 2000.

HOLANDA, S. B. d. Raízes do Brasil. São Paulo: Companhia das Letras, 1995.

HORKHEIMER, M. Autoridad y família y outros escritos. Barcelona: Paidós, 2002.

LI POVETSKY, G. A era do vazio: ensaios sobre o individualismo contemporâneo. Barueri, SP: Manoele, 2005. p. 59-110.

POCHMANN, M.; PEREIRA, M.; BARBOSA, M.; SILVA, R.; AMORIN, R. (Orgs.). Atlas da Nova Estratificação Social no Brasil. Classe média: desenvolvimento e crise. v. 1. São Paulo: Cortez, 2006. 
ROSSETI-FERREIRA, M. C.; AMORIM, K. D. S.; SILVA, A. P. S. d.; CARVALHO, A. M. A. (Orgs.). Rede de significações e o estudo do desenvolvimento humano. Porto Alegre: Artmed, 2004.

ROUDINESCO, E. A família em desordem. Rio de Janeiro: Zahar, 2003.

SENNETT, R. Autoridade. Rio de J aneiro: Record, 2001.

SILVA, A. P. S. d. (Des) continuidade no envolvimento com o crime - Construção de identidade narrativa de ex-infratores. São Paulo: IBCCRIM, 2003.

SILVA, E. R. A. d.; GUERESI, S. Adolescentes em conflito com a lei: situação do atendimento institucional no Brasil. Texto para Discussão no. 979. Brasília: IPEA, 2003.

VOLPI, M. ECA, delitos e adolescência. In: Adolescência, ato infracional e cidadania. São Paulo: ABONG/ Fórum DCA Nacional, 1997.

WAISELFISZ, J. J. (Coord.). Juventude, violência e cidadania: oS jovens de Brasília. Brasília: UNESCO, 1998.

\section{Endereço para correspondência \\ Samira Safadi Bastos}

Universidade Federal de Alagoas - Faculdade de Serviço Social - FSSO / UFAL

Av. Lourival Melo Mota, s/n - Cidade Universitária, Campus A. C. Simões - Maceió, AL, Brasil

Endereço eletrônico: sam.safadi@hotmail.com.

Elaine Pedreira Rabinovich

Universidade Católica do Salvador, Programa de Pós-Graduação em Família na Sociedade Contemporânea. Av Cardeal da Silva 205, Bairro Federação, Salvador BA, Brasil

Endereço eletrônico: elainepr@brasmail.com.br

Recebido em: 10/09/2010

Reformulado em: 10/12/2010

Aceito para publicação em: 15/04/2011

Acompanhamento do processo editorial: Rita Maria Manso de Barros

\section{Notas}

*Assistente social pela Universidade Federal de Alagoas - UFAL, Mestre em Família na Sociedade Contemporânea - UCSal e doutoranda pela Université Catholique de Louvain.

**Psicóloga, Dra em Psicologia Social pelo Instituto de Psicologia/USP; professora do Programa de Pós-Graduação em Família na Sociedade Contemporânea da Universidade Católica do Salvador.

${ }^{1}$ Dissertação de Mestrado defendida em setembro de 2008 no Mestrado em Família na Sociedade Contemporânea da Universidade Católica do Salvador - UCSal, da primeira autora, orientada pela segunda autora.

${ }^{2}$ Alguns autores utilizaram o conceito de classe média como conjunto demográfico que, embora com relativa pouca propriedade, destaca-se por posições altas e intermediárias tanto na estrutura sócio-ocupacional como na distribuição pessoal de 
renda e riqueza. Por conseqüência, a classe média é compreendida como portadora de autoridade e status social reconhecidos, bem como avantajado padrão de consumo. Neste sentido, englobamos a composição de classe média, composta por suas subdivisões de classe média alta, média classe média e classe média baixa, vinculando ainda, como propõem os autores supracitados, os estratos ativos e inativos. (POCHMAN et al., 2006, p. 16). 